\title{
Abortion and Family Planning
}

\author{
Affonso Renato Meira \\ Additional information is available at the end of the chapter
}

http://dx.doi.org/10.5772/intechopen.71772

\begin{abstract}
Abortion, a procedure by which the dead fetus is removed from the maternal organism and considered as a cultural trait, is found in all cultures of developed societies, as well as in the populations of aboriginal peoples. Moreover, it has long been a concern that has drawn social attention. It was only after in 1798, that the attention was drawn to the relationship between population and the production of goods. This concern has been accentuated by the birth rate and the longevity of human being. Abortion has undoubtedly interfered with population growth, the restriction of abortion advocated for human rights, or religious or economics reasons or by others. Family planning is a set of actions that help men and women plan for the arrival of their children, as well as prevent unwanted pregnancies. It is a project for couples to have offspring per their intentions and also the increase in world population that is worrying everyone has a decrease. For this, the Control of Birth is the method proposed to contain pregnancy. Abortion should only be recommended when a woman cannot or does not wish to give birth to a child or when the method used to control pregnancy has failed.
\end{abstract}

Keywords: family planning, birth control, artificial fertility, abortion, legislation, religion

\section{Introduction}

Culture for Edward Tylor "is all that complex that includes knowledge, beliefs, arts, morals, law, customs as well as all the skills acquired by man as a member of a society" [1] "The word culture, therefore, within an approach to the social sciences, includes everything that human beings have invented, built, adapted, or developed to survive and make life at least a satisfying and enjoyable experience, not only materially but also spiritually" [1].

Culture is an indivisible system that determines social behavior through traits, concepts, and patterns. Although it is an abstract process, culture sums up all the processes of reality that are 
learned in a slow but effective way. Being a learning process through communication between people, culture is a process that precedes and succeeds the components of a society. Thus, it is considered a historical phenomenon, but in another view, the cultural aspects being abstract are kept within the people and, in this sense, can be considered a psychological phenomenon.

The process of learning culture is a slow, continuous, unconscious process that begins at birth and continues throughout life. The culture of a society leads people to think, feel, and act per cultural standards. Cultural pattern is the orientation provided by the complexities and cultural traits that are valued in different ways. It is also in Piovesan's words the paths followed by the customs, ideas, beliefs, and attitudes of a population group. It is possible to consider that in all cultures, therefore in all societies, there is a standard in relation to health, which is composed of concepts grouped in medical knowledge that are characterized by traits, characterizing the behavior of society, at various levels in relation to health. Concepts are derived from medicine based on scientific learning or on empirical learning based on analogical knowledge.

Cultural trait is the least definable element (Kroeber) or identifiable (Herskovits) of culture [1]. Abortion should be considered a component of the standard of health of all cultures.

\section{Definition and indications}

Abortion is the process by which a dead fetus is expelled from the mother's womb. It is a process that occurs with all animals spontaneously. In human societies, it is a process that often occurs in women spontaneously or is carried out in a manner provoked by pregnant women in all cultures, a trait that is considered in a different way as determined by the legislation or the religiosity of the people. What varies is how different societies and consequently how diverse cultures determine how women should be followed.

Regarding whether spontaneous abortion occurs independently of the desire of the woman, we must help some inconvenience and take care that it is not repeated. Spontaneous abortion occurs in women of all social groupings regardless of existing knowledge.

Prolonged abortion can be performed by the oral route through drugs or medications or by performing surgical procedures.

Medicine considers that abortion is one of the events of obstetrics that occurs in a safe way, if the measures prescribed by the medical sciences are taken. Despite this, examining the determinations found in the different societies will lead to findings about countries where there is practically a total liberation for the realization of this event and countries in which the realization is penalized by the death of the woman and of those who carried out the abortion. Thus, an event of intimacy of the woman and of who should proceed to the abortion, in the most differentiated societies, the doctor has no shelter.

Family planning is a set of actions that help men and women plan for the arrival of their children, as well as prevent unwanted pregnancies. It is a project for couples to have offspring per their intentions and also the increase in world population that is worrying everyone has a 
decrease. For this, the Control of Birth is the method proposed to contain pregnancy. Abortion should only be recommended when a woman cannot or does not wish to give birth to a child or when the method used to control pregnancy has failed.

\section{Generalities}

Countries through legislation established by the government punish or liberate abortion. At the same time, the doctrine of various religions considers it to be a totally unwanted behavior. A cultural trait that turned into a medical fact is penalized by jurists and priests. Considered a medical act of which presents very little risk to the woman.

As a cultural trait, abortion on many occasions is not obeyed and not even penalized by women or society. This is because there are many reasons for women seeking abortion whether biological or social.

Among these reasons is rape, that is, the sexual act by violence and without the permission of the woman, which in almost all the countries of the Western world and countless of the Eastern world is considered a reason for the punishment of the man, as well as for allowing the woman to resort to abortion in order not to generate the fetus. In addition to rape, other reasons are considered for abortion.

Among the biological reasons are life-threatening or health-related injuries, such as the most relevant ones. The current knowledge of medicine is so developed that if abortion is used to save a woman's life, it is almost abandoned. The emergence of diseases produced by viruses leading to the birth of fetuses with abnormalities, such as anencephaly, that will produce harmful effects on the life of the newborn is also considered. In some countries, incest is remembered [2].

On the other hand, many social reasons are forgotten by many societies that consider, with greater weight, the position of several churches, among them more narrowly Catholic.

Among these social reasons, it is possible to enumerate at once the desire of the woman not wanting the birth of a child, which can occur through several factors: the lack of knowledge of the father; the disappearance of the father; the father's attitude in not recognizing the child; the lack of acknowledgment of childbirth by the woman's family, even causing expulsion from her home; the financial impossibility of the family to support another child; the impossibility of giving pause to a livelihood or future improvement activity; and finally the failure in the process of birth control.

Birth control has always been sought in ancient civilizations for more than 4000 years. In Egypt, the Berlin papyrus refers to fumigation that prevented pregnancy and the Ebers papyrus indicates procedures that prevented a woman from becoming pregnant for $2-3$ years. The Old Testament refers to the "coitus interruptus" method adopted in Europe in the nineteenth century and to this day adopted by poorer and less enlightened layers throughout the world.

The abandonment of unwanted children was practiced among the Greeks as well as among the Romans. Chinese were organized on farms for the reception of children who remained until they were sacrificed [3]. 
Beside infanticide, different, less bloody procedures have always been adopted by various societies.

Reali [3], citing Karl Martius, reports that among primitive peoples who inhabited Brazilian jungles, there was the habit of the Crowned, Purus, and Botocudos Indians to undergo bleeding to avoid pregnancy and to suffer blows in the womb to expel the existing fetus. Among the Pauamari Indians, Prance observed the practice of abortion using leaves of plants such as "Mabi kiri dadi (head of water snake) and Koaka-makha da-di," rubbed in the womb of pregnant women. The missionary couple Morgan found among the Indians of the Denis tribe located on the banks of the Juruá River in northern Brazil the use of a potion elaborated with Curarea Tecunarum that produces a contraceptive effect for 2 years.

Popular medicine has among its indications different bottles to produce contraceptive effect, still sought today by populations further away from the developed centers.

Even the most advanced societies that were guided by empirical methods were unconcerned with the situation of population growth. With the expansion of Christianity, the use of contraceptive methodology, almost always a product without a scientific endorsement, was being abandoned to resurface in the eighteenth century after the knowledge of Malthus' work. The work of Thomaz Robert Malthus came to light in London in 1798 under the title "Essay on the Principle of Population ..." Malthus was an important English economist of the late eighteenth and early nineteenth centuries. It was of great importance in the study of population growth in developing the so-called Malthusian theory. He was also a clergyman, university professor, demographer, and scholar. In his theory, Malthus affirmed that while the production of goods grew in arithmetic reason, the world population grew in geometric reason.

A methodology to avoid conception and, therefore, to produce the desired family planning was developing until reaching the recognition as a scientific area. From the second half of the twentieth century, especially in the 1960s, there was a population explosion. With an adaptation concerning historical conditions, it became known as the neo-Malthusian theory. This theory focuses on the population growth of underdeveloped countries; such growth would lead to scarcity of natural resources, as well as worsening poverty and unemployment. To avoid these setbacks, neo-Malthusians proposed effective birth control policies.

The Control of Birth was then sought with greater intensity. Procedures to prevent pregnancy began to be sought. Methods from the safe period resulted from the publication of two surveys conducted in 1923, alone by K. Ogino in Japan and by H. Knaus in Poland, to the process of the intrauterine device or the pills based on progesterone and estrogen, the most sought after 1950 that are intensively studied to verify the efficacy, the advantages, the disadvantages, the risk of failure, and the medical risk.

Without intending to deepen the various processes used in birth control, most of the most widely used methods will be judged by analyzing their advantages and disadvantages as well as the risks of failure and injury to women's health. 
The Safe Period method proposed by Ogino and Knaus, as well as the Basal Temperature method and the Ovulation method, is reasonably effective; as advantage, it does not need prescription and is accepted by religions. The disadvantage is that it requires a prolonged period of abstinence, and it has a risk of low failure and no medical risk [4].

The male mechanical device, known as condom or more popularly as small shirt, has moderate efficacy; as advantages, it does not need prescription and is low cost and as disadvantages are the strong motivation to use. It has a risk of low failure and no medical risk [4].

The female mechanical device known as diaphragm has a high efficacy if the use is accompanied using spermicide; has an advantage that requires only a brief medical education; and as disadvantage has the impossibility of not being able to be employed by all women. It has relatively low risk of failure and no medical risk [4].

Vaginal shower comprising the washing of the vagina soon after performing the sexual act proves to be practically ineffective; has the advantage of using sanitary facilities when they are nearby; and has the disadvantage of interrupting the love colloquy. It has a very high risk of failure and no medical risk [4].

Interrupted coitus, which consists of the interruption of sexual activity, has a much-discussed efficacy; as an advantage, can be realized at any time; and as disadvantage, reduces the sexual satisfaction of the couple. It has a risk of moderate failure and no medical risk [4].

Hormonal female contraception is based on the use of progestogen and/or estrogen to interfere in the ovulation, ovule transport, and nesting process, controlling the birth rate. Various avenues are used for its employment [5].

The oral progestogen is highly effective; has the advantage of being a single dose; and has the disadvantage of having a prolonged effect. It has a risk of failure, but a long-term medical risk [5].

Implants in various modalities are easy to implant and to remove, either subcutaneously or intramuscularly. It has high efficacy, with the advantage of slow release of progestogen, but with the disadvantage of facilitating irregular menstruations. They have low risk of failure [5].

Very common pills are prescribed either as a single monthly dose or with other doses. The efficacy is high, with the advantage of having no estrogen effects and with the disadvantage of presenting intermenstrual bleeding. They have risk of failure as well as medical risk [5].

Injectable steroids are given at intervals ranging from 1 to 6 months. They have very high efficacy and advantage of simple application, but with the disadvantage of presenting menstrual disorders and increase in body weight [5].

In this study, the effects of different methods of birth control, among those prescribed in the last years, were not found to be totally efficient, although some of them were highly viable in controlling the birth rate of the women who used them. 
It is evidenced that women who have used failed redundant methods of birth control and therefore failed to avoid pregnancy have the only recourse, if they do not really wish or cannot give birth for biological, social, or psychological reasons, to resort to abortion.

Medical abortion should only be performed by a physician in full exercise rights and knowledge, with the consent of the woman, without religious, ethical, or legal obstacles, and preferably during the first 12 weeks of gestation. The importance of this procedure has led the World Health Organization to make a publication on safe abortion that is already in a second edition [6].

Among so many events that worry those who care for health, abortion is highlighted by the difficulty in presenting appropriate measures to minimize its effects on the population. The problem of abortion presents a difficulty in promoting dialogs, since there are contradictory opinions. In the different societies, ideal values are found in relation to abortion, that is, its fulfillment in conditions necessary from the point of view of health and always complying with ethical and legal precepts. Yet the pattern of behavior shows that many times this ideal has not been attained and abortion is carried out in contravention of health, ethical, and law precepts. With liberality in its realization, abortion has long been a concern of societies.

In searching for references to abortion, one already finds that the Hebrews had a code that even punished those who practiced abortion with the death penalty. In Greek mythology, there is a quotation about Aristotle who was in principle opposed to abortion and then agrees to this procedure if the embryo was lifeless. Hippocrates-father of medicine-indeed the forerunner of medical ethics, was an oath-maker that doctors must follow, in which abortion practice is barred. The oath of Hippocrates held in the era before Christ is "I will not give the woman any abortive substance." In the Hammurabi Code, abortion is also punished. In Sparta, abortion was prohibited because of the need for men to take charge of internal security and to provide armies to intervene in times of war.

The issue of abortion became hot when St. Augustine spoke on the subject and then St. Thomas Aquinas differentiated the fetus formed from the fetus in formation. In the Roman Empire, the issue of abortion was also discussed [3].

Since the eighteenth century, despite the small interest that abortion caused in societies, its practice was deprecated, mainly because scientific knowledge had in the seventeenth and eighteenth centuries launched new foundations leading the fetus to be recognized as an autonomous entity accepting affirmations to echo the law.

With the French Revolution and the emergence of new nations, wars, plagues, and geographical discoveries, new changes occurred in the Western world, population growth slowed, while the need to maintain more effective armies increased. The life of men became valuable and motherhood was a patriotic activity [7].

The idea of a large family led governments in the nineteenth century to protect births for eminent political and ideological reasons, and with that direction, the population grew. After World War II, scientific knowledge revealed techniques and methods that allowed man to live longer. Even so, nations like France, Germany, and Spain have taken more restrictive measures to abortion. 
These legal measures and the other measures liberating the realization of abortion began to undergo a pressure of the doctrines of the religions, as of the action of the priests of diverse churches.

From the 1960s, a series of proabortion demonstrations led government officials to worry about these women-generated movements. With the development of scientific knowledge from the end of the 1970s, with new techniques of artificial fertilization, and with concern for population increase, a direction of the light of science has taken the path to prevent this advance. Thus, methods, techniques, uses, and even superstitions were reminded to avoid pregnancy and to avoid birth.

In the United States of North America, the guiding country of scientific education for less developed countries, there were movements so that abortion would not be penalized, as in Europe. From 1966 to 2009, 47 countries of the World Health Organization approved more liberal legislation on abortion, in contrast to 11 that have hardened it [8].

Preventing abortion facilitates birth while the release of abortion has the reason to prevent birth. It was not possible to calculate in what numbers these facts occur, but analyzing theoretically there is no denying that possibility.

The woman and the doctor decide about having/performing an abortion. These are the characters who, per the culture of the society in which they live, may have the freedom to perform it in a lawful, correct, and safe manner or hidden in the penumbra, in an illicit, much more insecure and incorrect way. However, whoever decides to allow or punish, the one who offers the condition of accomplishing it is the society through legislation leading to imprisonment or the church through sin, into the Catholic religion reaching excommunication.

In fact, not all religions consider abortion as a violation of their dogmas, as not all societies consider it to be an infraction of their legislation.

Thus, in various areas of the world, there are diverse opinions about abortion.

\section{Legislation}

Rodrigues Torres [2] presents a work comparing legislations of several nations in the twentyfirst century. The picture he presents regarding abortion is as follows:

A. prohibition of abortion, without exception: Malta;

B. abortion allowed at the request of the woman, with a certain time of gestation (from 90 days to 24 weeks): the United Kingdom, The Netherlands, Sweden, Romania, Denmark, Latvia, Czech Republic, Slovakia, Greece, Hungary, Belgium, Bulgaria, France, Germany, Lithuania, Estonia Portugal, Slovenia, Austria, and Italy;

C. abortion allowed because of life-threatening risk for pregnant women: the United Kingdom, Denmark, Sweden, Latvia, Poland, Slovenia, Austria, Czech Republic, Slovakia, Romania, 
Cyprus, Greece, Hungary, Spain, Portugal, France, Germany, Lithuania, Estonia, and Luxembourg and Ireland (includes risk of suicide);

D. abortion allowed due to risk of life for the pregnant woman, with some determined time of gestation: Holland and Finland;

E. abortion allowed because of health risks for pregnant women: Denmark, Slovenia, Austria, Czech Republic, Slovakia, Romania, Cyprus, Hungary, Belgium, Italy, France, and Germany;

F. abortion allowed because of risk to the health of the pregnant woman, with a certain gestation time (from 90 days to 28 weeks): Lithuania, Latvia, the Netherlands, the United Kingdom, Estonia, Ireland, Luxembourg, Portugal, Poland, and Spain;

G. abortion allowed when pregnancy results from rape or other sex offenses, including: Romania, Cyprus, Greece, Germany, and Hungary;

H. abortion allowed when the pregnancy results from rape or other sexual offenses with a certain period of gestation (from 90 days to 28 weeks): Denmark, Finland, France, Spain, Belgium, Poland, Italy, Luxembourg, Portugal, Lithuania, Estonia, Holland, and Latvia;

I. abortion is permitted when there is poor fetal formation, without gestation time: the United Kingdom, Austria, Czech Republic, Slovakia, Romania, Cyprus, Hungary, France, Germany, and Bulgaria;

J. abortion allowed when there is fetal malformation, with a certain time of gestation: Holland, Denmark, Sweden, Finland, Latvia, Estonia, and Luxembourg;

K. abortion allowed for socioeconomic reasons with a certain time of gestation: Holland, Finland, Italy, France, and Luxembourg.

In this work, there is also a passage on the nations of Latin America:

Cuba, which in 1965, legalized abortion up to 12 weeks of gestation and maintains a lower abortion rate of 21 per 1000 women of reproductive age, 10 points below the regional average.

El Salvador, Nicaragua, and the Dominican Republic criminalized abortion and did not allow exception.

In Chile, the Constitutional Court, in August 2017, passed a law authorizing abortion in case of death risk of pregnant women, when the fetus is not viable and in cases of rape.

In Honduras, because of the Code of Medical Ethics, abortion is allowed to save the life of the pregnant woman.

Argentina, Costa Rica, Venezuela, Peru, and Paraguay admit abortion to save the life of women, and in Argentina, the permit also covers when women do not understand reality and in Venezuela to protect the honor of women and men.

Uruguay, Colombia, Ecuador, Bolivia, Mexico, Panama, and Guatemala admit abortion in cases of rape or incest, while Uruguay also allows for cases of economic distress and Colombia, Mexico, and Panama allow when fetal malformation occurs. 
Brazil maintains that the criminalization of abortion is not punishable in case of rape or that there is no other way to save the life of the pregnant woman, and it is not considered a crime if the fetus is anencephalic.

Other countries where abortion is not allowed are Haiti, Suriname, Andorra, and the Vatican.

However, the internationally validated human rights system has already recognized that women have the right to freely determine the number of their children and the intervals between their births and to decide on their own bodies.

This exposition shows how the approach that the various nations give to the treatment to be offered for abortion varies. Different cultures have the same traits; others differ frontally.

\section{Religion}

Alongside the legislation of each country, there is a strong influence of the various religions in all cultures. It is calculated more than 3000 between sects and doctrines that have their dogmas and their peculiarities.

Catholicism as a religion was dominant for the first 1500 years in the Western world after Christ's presence on earth. In 1517, Martin Luther, a friar of the Order of St. Augustine, promoted a great movement breaking the unity of the Church. The Reform also addressed political and social aspects of conflict in Europe. In a major sense, the Reformation refers to other movements within the Catholic Church, such as that of Luther and that of Calvin in Switzerland, which originated the Evangelical Church and that of Henry VIII, in England from which the Anglican Church arose. These movements led to the Council of Trent, initiating a process of internal reform in the Catholic Church. Pope Francis in November 2016 extended to all priests the power to forgive the sin of abortion, which was only delegated to the bishops on a temporary basis. The pardon had already been authorized to all Catholic priests during the Year of Mercy, which ended on November 20 [2].

By Catholic doctrine, abortion means a serious sin punished with an automatic excommunication of those involved. Forgiveness can only be given by the priests who had this delegation of the Pope after a confession and repentance.

When one wants to analyze abortion by the religious eye, it is without doubt that the Catholic religion is the first to be observed and deserves the greatest attention. The Catholic Church is not the oldest, but it covers a period of approximately 2000 years and recounts the events of one of the oldest religious institutions in activity, influencing the world in spiritual, religious, moral, political, and socio-cultural aspects. The history of the Church is as follows:

Catholic is integral to the history of Christianity and the history of Western civilization [2].

The Catholic religion is spoken by the majority of the populations of the Latin nations in the world. Like others such as Anglican, Evangelical, Episcopal, Protestant, Lutheran or Calvinist, 
and many other sects or doctrines that adopt Christianity, it considers that the human being has life from conception. The followers of this religion do not accept the practice of fully liberalized abortion, since they regard their practice as the death of the unborn child. As for the unborn child, it is necessary that his life be preserved from conception [2]. According to Catholics, life is inviolable from conception, that is, from the moment of fertilization, from the union of the male sperm with the female egg.

Christianity predominates in the societies of the Western world, and being the greatest religion among those who venerate Jesus, the Catholic has its center in the Vatican State, which makes it to be the only religion that has under its rule a nation: the Vatican directed by the Pope. Catholic followers do not accept any reason to interrupt gestation which makes them different from others that justify abortion at specific times. Catholics believe that if they do not commit sins in the passage they are to fulfill on earth, they will have eternal life in heaven as their reward.

For this, the Catholics must fulfill all the obligations of the dogmas and doctrine of the Church.

Most western countries call themselves laymen, but not everyone is able to allow abortion without restriction.

Unlike the Catholic religion that its followers spread without a concern of grouping, the followers of the Jewish religion approach to practice mutual aid. Thus, the marriage generally of the Jews takes place between members of the same religion. It is common for Jewish colonies to have institutions such as hospitals for health care and schools for teaching, obeying religious precepts. Therefore, alongside traces of the cultures of the societies in which they live, the followers of Judaism retain traces of the culture of their religion. In Judaism, it is considered that the fetus or the embryo does not have the condition of person before the birth. Within the Jewish population of the world, which can be considered an ethnic group, there are distinct ethnic divisions, the majority being the result of the geographical ramifications of the Israeli population, and subsequently of independent evolutions [2]. Ethnic divisions among Jews were divided into two major divisions: the Ashkenazi and Sephardic. These two groups are characterized by the locality of habitation. The Ashkenazi settle more in the Anglo-Germanic part of Europe. Sephardic seek to live on the Latin side, while the Mizrahim and the Teimanim or Yemenite are located in the eastern part of the world. As far as abortion in the Jewish religion is concerned, if the embryo or the fetus is a risk to a woman's health, abortion is permitted among Orthodox, Conservative, and Reformist groups. Among reformers, welfare (social and psychological conditions) can be considered for the approval of abortion [2]. According to the tradition of Maimonides, in the twelfth century, if the embryo is to jeopardize the woman's life, mental, and physical health, she may interrupt the pregnancy in self-defense, since the embryo would be considered an aggressor. However, the decision must be made with a rabbi [2]. It is important to emphasize that compared with Christianity the traditionalism of the Jewish religion does not allow the interruption of pregnancy to be an individual decision of the woman, but that this desire be accompanied by the permission of the rabbi who in his wisdom finds it moral and fair [2].

From the Buddhist point of view, abortion is considered murder. However, there may be several motivations for ending the pregnancy. If the motivation is a selfish unconcern, such 
as not wanting to take care of a baby, it makes the act more serious in the eyes of Buddhism, because both the motivation and the act itself are destructive [2]. In Buddhism, motivation can also be positive. If the baby is greatly deformed or mentally deficient, then, wishing that the child avoids all future problems, abortion is not condemned because of the bodhisattva secondary vow given by all Buddhists if one does not avoid committing destructive action when motivation is positive. However, the ethics of the problem is still questionable. In another situation, in the case of risk to the mother during pregnancy, many factors and circumstances come into play to make a decision, it being defined that the karma consequent upon the decision will judge the individual in the next life depending on the circumstances of the abortion. In addition to causal motivations, Buddhist teachings dictate that contemporary motivation (what a certain individual thinks at the time of the abortion process) is also very important in justifying the act. In this way, it is fundamental for a Buddhist, who at the time of abortion, to have affectionate thoughts toward the baby [2]. Some Buddhist traditions perform ceremonies for the fetus. Supposedly, the performance of these ceremonies is extremely helpful to the "soul" of the mother. The fetus is named and prayed for their lives. The goal of Buddhists is to attain spiritual enhancement, the "nirvana" state of liberation from unhappiness and pain existing in the world, a spirituality of peace and happiness. Although there is no consensus in Buddhism on abortion, most of its followers consider a break from the precept of not taking life. Traditional Buddhist sources, such as the Buddhist monastic code, point out that the deliberate destruction of life is a serious breach of precepts. The current Dalai Lama considers abortion to be erroneous but believes there can be occasions to justify it [2]. Even when abortion is done to save a woman's life, it is almost always seen as causing suffering and negative karma.

The followers of Islam, although the Koran condemns the act of killing, are very much attached to a fanaticism to follow, for example, to war, in which they do not bother to die, with the idea that death brings them to the presence of Ala. This fanaticism has, in these times, reached the belief of guys that often burst bombs affixed in their bodies, in places crowded with people intending to commit acts of terrorism and without the concern of dying. The main cause of abortion condemnation among Muslims lies in historic roots [2]. The Bedouin peoples saw in infanticide and abortion a concern because of the need for men to equip armies for the desired expansion in Africa, Asia, and Europe. The attitude of these terrorists is reprehensible, therefore, that they are carried out in wars of conquest, including because the colonization of peoples by the Islamists was much more permissive than the European process in the Americas [2]. In the Islamic faith on the last day of mankind, the children will be witnesses against the parents who killed them. Issa refers to the children who would have been born and whose birth was interrupted [2]. Most followers of Islam consider abortion to be permitted up to 120 days from gestation when the fetus or embryo has a similar life condition to animals or plants, and for this reason, it is the maximum limit for the practice of abortion regardless of the fact which leads to it. In the case of women's risk of life, for Islam, it will be preferable to save the main life, that is, the life of the mother. If a pregnancy is accidentally interrupted, an indemnity must be paid to the father since through the accident the life of an embryo is lost. The value of the life of an embryo is different from the life of a fetus. If the pregnancy is interrupted before 
the fifth month of gestation, $10 \%$ of the value of a life must be paid to the father, if it is then the value will be the total of a lifetime [2]. Abortion in Islam is permitted if there is an acceptable justification. There are, however, groups for which termination of pregnancy is unacceptable.

Hinduism is a religion that contains several gods that are venerated on diverse occasions and sites. However, in a general sense, it classifies abortion as an abominable act. It is a kind of union of beliefs with lifestyles. Their religious culture is the union of ethnic traditions. It is currently the third largest religion in the world by number of followers. It originates in approximately $3000 \mathrm{BC}$ in ancient Vedic culture. Its followers respect old things and tradition, believe in sacred books, believe in deities, persist in the caste system, determine the status of every person in society, know the importance of rites, rely on spiritual guides, and believe in the existence of previous incarnations. The birth of a person within a caste is a result of the karma produced in past lives. Only the Brahmins belonging to the "superior" castes can perform the Hindu religious rituals and assume positions of authority within the temples [2]. Among the principal gods are Brahma who represents the creative force of the Universe; Ganesha, goddess of wisdom and luck; Matsya who saved the human species from destruction; Sarasvati, goddess of the arts and music; Shiva, the supreme god and creator of yoga; and Vishnu responsible for the maintenance of the Universe [2].

The Church of Jesus Christ of Latter-day Saints, the Mormons, does not advise abortion; on the contrary, it opposes. However, if it is to preserve the health of the woman or if the pregnancy is the result of rape, in this case to save the woman's spiritual health, the procedure is allowed by the President of the Church after consulting a doctor. The nicknames of Mormons were created by non-Church members to refer to members of the Latter-day Saints movement. The name comes from a considered sacred scripture book compiled by the ancient Mormon prophet, entitled The Book of Mormon, Another Testament of Jesus Christ. According to the official version of the church, the name given by the Lord, by which the members of the Church are to be known, is Latter-day Saints [2]. The doctrine of the church changed before the glorious day of the second coming of Jesus Christ including "of the last days" to designate the members of the church. The word Mormon originates in the Book of Mormon, a book compiled by the Mormon prophet, which was named after a place where the people of King Noah lived and which according to the Prophet Joseph Smith himself means simply "very good" [2]. The Mormons have their principal headquarters in the United States of North America where their first Church was formalized on April 6, 1830. The main center is located in Salt Lake City in the State of Utah; Mormons spread throughout the world on a missionary mission preaching Christianity and capturing new followers [7].

For followers of Protestant churches Baptist, Lutheran, Presbyterian, there is a range of attitudes toward abortion. In the religious doctrine of Protestants, there is a greater range of attitudes toward abortion than in the Catholic Church.

The great difference between Catholics and most Protestant churches is in respect for their mother's life. Thus, among Protestants, all agree that it is at the moment of conception that the mother acquires all the personal rights and rights attaching to motherhood, since she is in charge of gestating, caring, and feeding the embryo from the moment of its conception until 
the moment of its birth. At the same time, it is necessary to see that the doctor has the primary duty to the mother, because she was the person who requested it. Thus, if a choice has to be made between the life of the mother and the life of the embryo or the fetus, the priority choice will always rest upon it, and so the doctor must decide, in the last analysis, when he can detach the mother from his responsibility in relation to the fetus. Protestant countries were the first in this century to adopt more liberal legislation on abortion [2].

The Anglican Church is considered by many to be Catholic because it does not adopt heresies in its statements of faith. But it is not "Roman," it is not subject to the Pope, nor does it adopt its particular dogmas and practices as: transubstantiation of the elements of the Eucharist; prayer for the dead; compulsory celibacy of parents; veneration of the virgin Mary and the canonized saints; immaculate conception of Mary; Mary's bodily assumption into heaven; the sacrifice of the mass; purgatory; infallibility of the pope; meritorious works for the salvation of the soul; the tradition with the same value of the Holy Scriptures; and others. As far as abortion is concerned, there is a permit that can be made, despite the fact that many followers of the Anglican Church oppose abortion [7].

Methodists admit abortion in special situations, that is, in case of rape or the health or life of the pregnant woman is in danger of life.

The Spiritists who follow Allan Kardec's book are opposed to abortion even in cases where the woman has been raped. They believe that malformed fetuses should be born because they lead parents to an ordeal that must pass through their lives [2].

The Universal Church of the Kingdom of God is a Christian, evangelical, neo-Pentecostal denomination based in the Temple of Solomon in the city of São Paulo, Brazil. Founded on July 9, 1977, by Edir Macedo, it became one of the largest Brazilian neo-Pentecostal groups. According to estimates, there are more than 6000 temples, 12,000 pastors, and 1.8 million faithful followers around the country. There are about 8 million followers and 15,000 pastors in 105 countries, being more popular in Portuguese-speaking nations. It is one of the largest religious organizations in Brazil and the 29th largest church in numbers of followers in the world [7]. In a public statement made more than 10 years ago, and recently reaffirmed, Pastor Macedo clarifies that he is in favor of women's right to choose and in this case in favor of abortion if it is the desire of the woman [2].

Jehovah's Witnesses are a Christian sect that has adherents in 240 countries and autonomous territories, with about 8 million practitioners, even though they congregate a greater number of sympathizers [2]. They are known for their regular and persistent work of preaching their principles and dogmas from house to house, on the streets, and in public places.

They worship exclusively the God who is presented in the Bible, calling him by the name Jehovah, and they are followers of Jesus, possessing a different concept from the other Christian groups that, for the most part, believe in the concept of a Triune God. They claim to follow biblically the instructions left by Jesus Christ, but reject the classification of being fundamentalists in the sense in which the term is commonly used. They seek to base all their practices and doctrines on the content of the Bible. Their organization is underpinned by financial donations provided by Jehovah's Witnesses worldwide. Voluntary donations are important but not vital to maintaining and expanding the number of witnesses who dedicate 
their time in their educational work respecting the laws of each country, having legal representation, and are thus legally established as a nonprofit organization [2].

As far as abortion is concerned, there is no definitive positioning, since if they consider that interrupting life is a serious sin and that the fetus is a living being, they accept that the societies in which they are inserted have as correct and legal the established regarding the abortion [2].

Sex and sexual pleasure are accepted as desirable practice among those who follow Taoism and Confusion. This practice should be observed in moderation, which should also be considered in relation to reproduction and abortion as an acceptable resource. However, groups of Taoists aiming at preserving life adopt views contrary to abortion [2].

Other extant religions do not have many followers who may be involved in abortion either because they permit or restrict abortion.

Religions and beliefs are scattered throughout the world with evidence of a higher percentage of each of them in the various areas of the planet: the Catholic religion in South and the Center America and in the Latin countries of Europe; the Jewish religion in Israel and in all parts of the world; Protestantism in its different preaching in Europe in the Anglo-Germanic areas, as well as in the United States and Oceania. In Asia, the predominant religions are Buddhism, Islamism, and Hinduism more or less preaching about abortion.

From this summary analysis of family planning, there is no doubt that birth control is the process of choosing to avoid the growth of the population in order to meet the wishes of couples. In the occurrence of the failure of the proposed methods, abortion can only be used to avoid birth. However, abortion, despite being a safe and effective procedure, is under pressure from population groups motivated by what is established by law as well as by religious beliefs.

We need to focus on who wishes the pregnancy does not wish to abort it; who wishes to abort could not have or does not want the child; medicine is not contrary to abortion; nor the woman, nor the doctor are obligated to make the abortion; who decides for allowing the procedure is the society.

\section{Final regards}

In different societies of which the world is made of, there is a great disagreement that occurs in the legislation and what the beliefs are. That different considering the abortion happens innumerous opportunities in that same societies that on one side the abortion as prohibited by law, but in many others the church with its vast kinds of faith see abortion as inevitable. This differentiation of acceptance in the family planning, of birth control and artificial fertilization, still worth concerning ends up left aside as a minor issue.

The family planning, the birth control, and the artificial fertilization in almost all societies, especially the more modern, are habits comprehended and possible to appeal, whatever reason it is necessary. 
These variations are due to, in fact, another point of cultural difference. It is a discussion about who decides if an artificial fertilization must be made or should look to an abortion. That usually occurs when the reason for the debate is whether the fetus is a human being.

Life is continuous, since its beginning the world never let it go. The discussion must rely upon the subject of when the biological being, product of a union of two living cells, the male gamete and the female, is considered a person. The conception consists in the union of two cells that multiply themselves building a conglomerate of cells that constitute a human being, which starts to be considered a person when it personalizes, meaning, when it acquires a life nonvegetative. There is nothing to mistake between a cell conglomerate and a human being. This is an ancient concern in studies, since Greece of Aristotle, we have been looking for an answer to that question. Without offering an answer, we can develop some thoughts.

The idea that from the ovule fertilization a new life emerges used to be predominant in scientific and ethical position if not accepted was not discussed. This concept led us through time, until it started to be polemic and led to ethical positions that presented contradictions and that modifies to attend the changes of technology and medicine in the human reproduction area and followed in whatever possible religious dogmas. The scientific evolution resulted in a changing in ethical position, not of those that were stuck to their religious dogmas, but to those others that considered a secular position.

The technological development of human fecundation extracorporeal, aiming at the possibility of transferring of embryo produced "in vitro" fertilization to the organism of a woman, led to a different ethical perspective.

Who should decide regarding the living being that is located in the uterus of the woman? A fundamental answer is to decide which procedure the family will use, whether that is artificial fertilization or the realization of the abortion.

The development of medicine in the example of the transplants and the possibility of human reproduction made by an assisted way brought, mainly, to those who considered life as something sacred a sensation of no safety with what was happening in this sector. Considering life as something holy, independent of the knowledge of doctors, had nothing to do with praying and waiting for divine solution.

The reflections prevenient of the academics complemented with other layers of society that brought light to the knowledge acquired by different forms of coming to the philosophical, empirics, analogic, and scientific.

The defenders of the thesis of heteronomy considered a child as a new being, although, a result of the mother, she is detached from the conception moment. In that way, it is not up to the woman to decide for the abortion, which would be homicide of the newborn.

On the other side the thesis of autonomy, by autonomy it is understood that the right of the patient to be correctly informed of its health situation and which is the action offered by the doctor, as how which are the possibilities of final results expected and having the right to offer its acceptance or not. The autonomy is self-governing, the capability to decide what is considered 
good and what to receive the best. The defenders of that thesis consider that the woman is the one who should decide for the birth control, for the family planning, and for the abortion.

From the heart of this discussion about virtues and truths and opinions about beliefs and laws, variables in diverse and different societies, it is hard if not impossible to arrive at an answer. It involves existing moral aspects.

In general, the conception driven away from laws and beliefs, the decisions should rely in the doctors' opinion because they should know, orient, and practice those processes, tied to the knowledge of science. Knowledge like these that in modern society belongs to doctors, independent of laws and of society's laws and religion. There is no doubt that the process of family planning is mutually related to birth control, and in artificial fertilization, it is being related to all those students of medicine in any area of the globe, such as the techniques of abortion. The same relates to ethical and moral aspects of medicine, that for legality reasons need to attach to the determination of legal standards in all countries, independent of their political position.

Of all ways, the final decision goes to the mother. There is no living human being that did not come from a mother, always biological, is real, being that uterus rented or borrowed, today known as belly for rent. The father not always is known; in different societies, many children do not know their father.

Until the beginning of the past century, the 1920s of the twentieth century, humanity did not have the real concern with population increase. There was room for everybody. It was after that time that Malthus' concerns appeared and medicine and science began to have a more emphasized point of view with population aspects in the globe. It was the beginning of the birth control and afterward a little more over half the century the first test-tube baby came to life, consolidating the artificial fertilization that is made in such a number that it is impossible of being recognized that the conception was made in a laboratory.

The first test-tube baby of the world was called Louise Brown and was born in July 25th of 1978, in Bristol, England. Living in England, she has two children that were born of natural birth. She has a sister, also brought to life in an artificial environment. Time has passed; with the successful attempt made in England, others were made throughout the world. Australia, in 1980, had its first successful attempt. In 1981, the first test-tube baby from the USA was born. In the following year in France a new test-tube baby was born. It was only in 1984 in Brazil, São José dos Pinhais, in Paraná 7th October came to life Anna Paula Caldeira. In 1986, it was Portugal the home land of a test-tube baby that played professional Football in his early years.

In the present, nothing more concerns the world that has seen much successful artificial fertilization with the birth of a new child came from three human beings, two women and a man, not only more than a father and a mother. And what is to come?

"The future belongs to god" some would say. Will they be right? It was believed by some that children were prevenient of a holy will and that no man could give birth without god's will.

According to different cultures, in which religious values are strong, doctrine, and dogmas of various existing religions, the beginning of life is given in the moment of the conception, meaning, in the union of the male spermatozoid with the female ovule. Others beliefs more liberal consider different and diverse occasions. Still in respect to considering when the 
beginning of life is, there are some aspects to have in mind, and other theory defends that a personality of a person begins at birth.

This era of significance of reunions brought people of various positions to discussion about what society should accept. Today, these discussions are highly forgotten, and it seems that science overcame once again the beliefs, as it occurs when time passes.

Anyhow, still the problem of the beginning of life is not well stabilized. To many, the biological being prevenient of the union of male and female gamete is considered when a person has fulfilled three conditions:

In the biological field in his relation to the environment he is going to live in.

In the social field in relation to the people with whom he is going to coexist.

In the spiritual field in relation to the supernatural of any institutionalized form of religious churches or any other, but oriented by one form of values that he will believe.

Others consider a person only when he has a civil register in the book of registers, with his name, place of birth, and date of birth.

Little attention was paid to the fact that many times this union occurs after innumerous attempts and tiring efforts made in the laboratory to achieve this goal. And more is to be considered with the new experience declared, how have the objective achieved, realized with the material that came from two women and a man.

In the past, the idea of a new life would initialize in the fecundation of the ovule, if spread through scientific ways and ethical if not, totally accepted and not discussed. It was the word of the religion that prevailed.

In many occasions, during these procedures of artificial fecundation, during transfers, large quantities of embryos may evolve. The technique predicts the reducing of embryos that will be discarded if frozen for a period of maximum 5 years, to be then eliminated. It brings up the question that this technique could be considered abortive at least to those who consider as a human being the embryo since its fecundation. Still the respect to consider when it is given the beginning of life is something to have in mind. Another theory defends that life occurs when the personality develops. That usually happens in the eastern world, in which the attention to the new being only concretes itself at birth.

The beginning of life is a concern that comes always to be discussed mainly in the religious perspective. Life since its first beginning never ceased to exist; the living beings die and are replaced by others, and so it has been for as long as we know. What is discussed is when a complex cause by the union of biological cells transform or is considered a person. This doubt comes also in the form of mythology from Asclepius, Aristotle, and Hippocrates, which is not solved until today.

The abortion in all of its religious and ethical aspects bring more difficulties in producing a unity of opinion in societies. In some, aborting is totally prohibited in others, the process is liberated; and between these two extremes, we found some that operate with some barriers.

Women's role in one culture is for sure relatively different in countries around the globe. In the eastern part of the world, the position of woman can sometimes go as high as being the 
leader of the nation. Such event occurred in Brazil, Argentina, Germany, Chile, and others, as it is permitted by law. In other countries, the women are segregated from man in various activities such as being with her husband and her friends as well as it is prohibited to go to the beach with bikini. Some cultures ask for the women to cover the face at all times and some do not even allow them to drive cars.

The women's sexual aspect tends to vary as time changes and as society shapes it.

Between all aspects, the ones that are tied to the population's health are to be looked closely. The aspect of abortion regulation is a problem that shows a hard example for dialog building due to the fact that there are very opposite opinions. Values and aspects for dealing with sex and abortion by the health system point of view vary within society's ethical and legal standards. Anyway, the pattern of behavior shows that in many situations the ideal way to deal with the abortion is far from what is indeed done, breaking ethics, laws, and health protocols. The scenario shown allows us to interpret that countries with different religious aspects, geographical location, and political system do treat the abortion theme differently. The abortion as well as the artificial fertilization, family planning regulation, is much more a socio-political aspect of life than scientific, even though the risk of an intervention is very low.

What we can learn going through history is that abortion legalized or prohibited according to its cultural aspects is always a practice within the society. Legislation of all countries has gone in different ways following the scientific and social founding. Basically, two different positions are very evident.

One of this positions deny the possibility of the realization of the abortion process in any condition, usually tied to the catholic followers, and of others that consider that the life of a person starts in the conception, that being, when the sperm meets the ovule. It is a position defended by other churches and religious groups that say that life starts before the act of being born as the Islam and Judaism say. Others consider that life starts when the person is born, when the biological has in society a social position as a person. The different beliefs tend to alter the human being's positions. It is not a matter of criticizing but to respect. Anyhow, it is important to quote that Gafo, Spanish catholic priest, in his writings shows a different approach using the bible saying that it does not condemn abortion explicitly.

Another position is the one of acceptance of the abortion process, with or without some regulation. It is without a doubt the biggest position in the world. The abortion made with a justifiable argument does not face any kind of punishment. The variations occur in types of justifications accepted and go from the very rigorous to almost stopping the realization. The most accepted justifications are the abortions that are called therapeutic in which the life of the pregnant woman is in danger, whereas the eugenic abortions are made when the fetus shows anomalies. Apart from these cases, the other reason is that the pregnancy is a result of rape or an incestuous relation.

These justifications are based on defending the woman's health. Justifications for social reasons are not remembered, but by those, innumerous women are led into making an abortion in an illicit way. 
As for the abortion, the doctor has almost always the same concern to, varying very little from society to society, what concerns are the religious belief and the local legislation in which the Hippocrates oath is sworn. In this oath, made by Apollo the doctor, Asclepius, Hygeia, and Panacea, it is said that one shall never give abortion substances to his/her patients. The fundamental is not to suffer any problems with the local legislation.

Women, on the other hand, besides having the legislation concern, that in some countries can led to death penalty also have the religious concern. The doctor makes the procedure when searched by a patient because it is his duty. The woman looks for it for many reasons. The main and most frequent reason that leads a woman into this path is rape, known internationally as a valid and justifiable reason and legal in many countries. Other reasons are the therapeutic reason, the eugenic, and the incestuous. Women claim the abortion justification in many reasons, especially when the presence of fetus with anomalies in formation is noted, which leads them into a small life after birth. This last point exemplifies well the important fact for quality of life: which life quality that a very poor women can provide for a child that was abandoned by his dad or kicked out of her house by the family? Unfortunately, these aspects are usually not accounted.

The abortion liberation finds its support in the autonomy right. The woman desires, the protection of the female health, the condition of the family, the consent or not of the partner are reasons for which the abortion is made. All humans should be responsible and able to decide for themselves regardless of which reason justifies this action. This choice between the woman and the doctor should not be made under the black market.

The woman who is openly informed of the risks submits herself to this kind of procedure and decides what is best in a transparent way; scientific medicine is considered the best at maximum 12 weeks for the process to be made.

The problem of abortion is to be considered the most important aspect of family planning, artificial fertilization, and birth control, which are of less resistance in other societies.

\section{Author details}

\section{Affonso Renato Meira}

Address all correspondence to: armeira@usp.br

Faculdade de Medicina, Universidade de São Paulo, São Paulo, SP, Brasil

\section{References}

[1] Meira AR. Society and Health: An Introduction to the Notions of Social Sciences Applied to Health. Campo Grande: Federal University of Mato Grosso do Sul; 1997. 104 pp 
[2] Meira AR. Abortion: Introduction and Perspectives. Saarbrücken: New Academic Editions; 2017. 84 pp

[3] Reali E. Evolution of World Population Growth in Meira, A.R. Notions of Family Planning and Birth Control, São Paulo, A.R. Meira. 1982. 21/40 pp

[4] Martins AM. Methods of Sexual Abstinence in Meira, A.R. Notions of Family Planning and Birth Control, São Paulo, A.R. Meira. 1982. 79/82 pp

[5] Pereira DHM. Female Contraception in Meira, A.R. Notions of Planning and Birth Control, São Paulo, A.R. Meira. 1982. 87/110 pp

[6] Grafica SA. World Health Organization. Safe Abortion: Technical and Policy Guidance for Health Systems. 2nd ed. (Translation to Portuguese, Silvia Piñeyro Trias)

[7] Scherer DO. Abortion, some uncomfortable reflections. The State of São Paulo A2 Open Space. December 10, 2016

[8] BBC. Brazil Abortion gains space in several countries of the world 